ISSN : 2615-1995, E-ISSN : 2615-0654

J. Madani., Vol. 4, No. 2, September 2021 (126 - 132)

(C)2018 Lembaga Kajian Demokrasi

https://doi.org/10.33753/madani.v4i2.169

\title{
Analisis Investasi Saham Dengan Menggunakan Pendekatan PER dan PBV Pada Perusahaan LQ 45 yang Terdaftar di BEI Periode 2015 - 2019
}

\author{
Iriana Kusuma Dewi \\ Fakultas Ekonomi dan Bisnis, Universitas Pamulang \\ dosen01729@unpam.ac.id \\ Vidya Amalia Rismanty \\ Fakultas Ekonomi dan Bisnis, Universitas Pamulang \\ dosen02270@unpam.ac.id \\ Ading Sunarto \\ Fakultas Ekonomi dan Bisnis, Universitas Pamulang \\ dosen02153@unpam.ac.id
}

\begin{abstract}
Abstrak
Tujuan penelitian adalah untuk mengetahui dan menganalisis pengaruh Price Earning Ratio (PER), dan Price Book Value (PBV) terhadap harga saham beredar pada perusahaan-perusahaan LQ45 yang terdaftar di Bursa Efek Indonesia (BEI) periode 2015-2019. Metode yang digunakan dalam penelitian ini menggunakan metode deskriptif kuantitatif. Populasi dalam penelitian ini adalah seluruh perusahaan-perusahaan LQ45 yang terdaftar di Bursa Efek Indonesia yakni sebanyak 45 perusahaan. Sampel yang digunakan dalam penelitian ini sebanyak 28 perusahaan pada periode 2015-2019. Hasil yang diperoleh dari perhitungan rata-rata PER yakni ADRO 0.11, AKRA 2.03, ASII 1.45, BBCA 8.74, BBNI 1.06, BBRI 0.79, BBTN 2.88, BMRI 2.01, GGRM 1.73, HMSP 3.77, ICBP 2.69, INDF 1.27, INTP 3.46, JSMR 2.00, KLBF 3.02, LPPF 1.72, MNCN 1.30, PGAS 22.96, PTBA 2.21, PTPP 1.46, SCMA 1.88, SMGR 2.31, SRIL 0.09, TLKM 1.36, UNTR 14.28, UNVR 4.75, WIKA 1.51, WSKT 1.47. Serta PBV yakni ADRO 1.1, AKRA 1.0, ASII 1.2, BBCA 1.6, BBNI 1.4, BBRI 1.5, BBTN 1.2, BMRI 2.6, GGRM 3.1, HMSP 1.1, ICBP 5.1, INDF 1.3, INTP 3.0, JSMR 2.1, KLBF 5.2, LPPF 4.6, MNCN 2.0, PGAS 1.7, PTBA 0.5, PTPP 0.2, SCMA 0.8, SMGR 2.1, SRIL 0.016, TLKM 0.2, UNTR 1.9, UNVR 0.6, WIKA 0.2, WSKT 0.1. Berdasarkan hasil penelitian dapat disimpulkan berdasarkan perhitungan PER dan $P B V$ terdapat 11 perusahaan yang berada pada posisi undervalued (saham dinyatakan murah dan layak untuk dibeli) yakni AKRA, BBRI, HMSP, PTBA, PTPP, SCMA, SRIL, TLKM, UNVR, WIKA, dan WSKT. Sedangkan sisanya untuk hasil perhitungan PER dan PBV ada yang berada pada posisi undervalued dan overvalued.
\end{abstract}

Kata Kunci : Saham, Investasi, PER, PBV.

\section{Abstract}

Financial statements show information about the state of a company that can be used as a source of information for decision making. The purpose of this study was to determine and analyze the effect of Price Earning Ratio (PER), and Price Book Value (PBV) on the outstanding stock prices of LQ45 companies listed on the Indonesia Stock Exchange (IDX) for the 2015-2019 period. The method used in this research is descriptive quantitative method. The population in this study are all LQ45 companies listed on the Indonesia Stock Exchange, which are 45 companies. The sample 
used in this study were 28 companies in the 2015-2019 period. The results obtained from the calculation of the average PER are ADRO 0.11, AKRA 2.03, ASII 1.45, BBCA 8.74, BBNI 1.06, BBRI 0.79, BBTN 2.88, BMRI 2.01, GGRM 1.73, HMSP 3.77, ICBP 2.69, INDF 1.27, INTP 3.46, JSMR 2.00, KLBF 3.02, LPPF 1.72, MNCN 1.30, PGAS 22.96, PTBA 2.21, PTPP 1.46, SCMA 1.88, SMGR 2.31, SRIL 0.09, TLKM 1.36, UNTR 14.28, UNVR 4.75, WIKA 1.51, WSKT 1.47. Serta PBV yakni ADRO 1.1, AKRA 1.0, ASII 1.2, BBCA 1.6, BBNI 1.4, BBRI 1.5, BBTN 1.2, BMRI 2.6, GGRM 3.1, HMSP 1.1, ICBP 5.1, INDF 1.3, INTP 3.0, JSMR 2.1, KLBF 5.2, LPPF 4.6, MNCN 2.0, PGAS 1.7, PTBA 0.5, PTPP 0.2, SCMA 0.8, SMGR 2.1, SRIL 0.016, TLKM 0.2, UNTR 1.9, UNVR 0.6, WIKA 0.2, WSKT 0.1. and PBV are ADRO 1.1, AKRA 1.0, ASII 1.2, BBCA 1.6, BBNI 1.4, BBRI 1.5, BBTN 1.2, BMRI 2.6, GGRM 3.1, HMSP 1.1, ICBP 5.1, INDF 1.3, INTP 3.0, JSMR 2.1, KLBF 5.2, LPPF 4.6, MNCN 2.0, PGAS 1.7, PTBA 0.5, PTPP 0.2, SCMA 0.8, SMGR 2.1, SRIL 0.016, TLKM 0.2, UNTR 1.9, UNVR 0.6, WIKA 0.2, WSKT 0.1. The conclusion of this researches based on $P E R$ and $P B V$ calculations, there are 11 companies that are in an undervalued position (shares are declared cheap and worth buying) namely AKRA, BBRI, HMSP, PTBA, PTPP, SCMA, SRIL, TLKM, UNVR, WIKA, and WSKT. While the rest for the calculation results of $P E R$ and $P B V$ are in the undervalued and overvalued positions.

Keywords : Shares, Investment, PER, PBV.

\section{PENDAHULUAN}

Nilai perusahaan merupakan persepsi investor terhadap tingkat keberhasilan perusahaan yang terkait erat dengan harga sahamnya (Sujoko dan Soebiantoro, 2007). Saham merupakan produk investasi yang menawarkan para investor untuk lebih leluasa dalam berinvestasi dikarenakan para investor bisa melakukan perubahan arah terkait jual beli saham yang dimiliki. Investasi saham dilakukan melalui pasar modal (capital market). Tujuan pasar modal di Indonesia adalah untuk mengerahkan dana dari masyarakat guna disalurkan ke sektorsektor yang lebih produktif, serta ikut mewujudkan pemerataan pendapatan melalui pemilikan sahamsaham perusahaan. Sampai saat in minat orang Indonesia untuk berinvestasi di pasar modal mengalami peningkatan dimana pada tahun 2019 tercatat ada sebanyak 2,48 juta investor, jumlah ini mengalami peningkatan dibanding tahun 2018 yakni ada sebanyak 1,61 juta investor.

Investasi pada saham merupakan investasi sector finansial yang tergolong high risk-high return investment. Salah satu resiko dari investasi saham adalah harga saham yang cenderung fluktuatif, jika investor membeli saham dengan harga relatif kecil bukan berarti harga saham tersebut pada tahun selanjutnya akan tetap sama. Saham tersebut ada kemungkinan mengalami kenaikan atau penurunan harga. Oleh karena itu sangat penting bagi investor untuk melakukan analisis investasi saham guna meminimalkan resiko. Seringkali hasil analisis harga saham tidak memiliki nilai yang sama dengan harga saham yang diperdagangkan di pasar modal. Menilai harga saham juga merupakan hal yang mendasar dan harus diketahui oleh investor dengan memahami pentingnya penilaian saham dapat membuat para investor tahu kapan harga saham berada pada posisi overvalued yaitu suatu keadaan yang terjadi apabila nilai wajar (nilai intrinsik) lebih rendah dari harga yang diperdagangkan di pasar modal, kondisi ini mengharuskan investor untuk menjual sahamnya apabila investor sudah terlanjur membeli. Kemudian posisi undervalued yaitu suatu keadaan yang terjadi apabila nilai wajar (nilai intrinsik) lebih tinggi dari harga yang diperdagangkan di pasar modal, kondisi ini berarti saham tersebut layak untuk dibeli.

Analisis atau penilaian harga saham perlu dilakukan sebelum mengambil keputusan investasi. Menurut Damodaran dalam Suryanto (2016), penilaian harga wajar saham adalah proses membandingkan nilai riil suatu saham dengan harga yang berlaku di pasar dengan memperhatikan faktor fundamental. Faktor-faktor fundamental yang mempengaruhi nilai biasanya lebih lambat perubahannya dibandingkan perubahan harga pasar. Di dalam pasar yang tidak sempuna, penilaian saham dapat melokalisir variances (perbedaan) antara nilai wajar dengan harga permintaan menurut pasar.

Salah satu analisis fundamental yang dapat 
digunakan untuk menilai kewajaran harga saham adalah Price Earning Ratio (PER) yakni hubungan antara pasar saham dengan earning per share saat ini yang digunakan secara luas oleh investor sebagai panduan umum untuk mengukur nilai saham. PER menunjukkan berapa kali lipat para investor di pasar mau membayar untuk setiap rupiah laba per saham yang dihasilkan perusahaan, sehingga PER mencerminkan daya tarik sebuah saham. Kegunaan Price Earning Ratio adalah untuk melihat bagaimana pasar menghargai kinerja perusahaan yang dicerminkan oleh Earning Per Share. Perusahaan dengan peluang tingkat pertumbuhan tinggi biasanya mempunyai Price Earning Ratio yang tinggi pula, dan hal ini menunjukkan bahwa pasar mengharapkan pertumbuhan laba di masa mendatang. Sebaliknya, perusahaan dengan tingkat pertumbuhan yang rendah cenderung mempunyai Price Earning Ratio yang rendah pula. Semakin rendah Price Earning Ratio suatu saham maka semakin baik atau murah harganya untuk diinvestasikan (Nugraha E. S dan Sulasmiyati S, 2017:107).

Price book value (PBV) merupakan metode penilaian saham yang berdasarkan pada book value. Book value merupakan nilai dari ekuitas dibagi dengan jumlah saham yang beredar atau nilai ekuitas perlembar saham. PBV yang tinggi mencerminkan harga saham yang tinggi dibandingkan nilai buku perlembar saham. Semakin tinggi harga saham, semakin berhasil perusahaan menciptakan nilai bagi pemegang saham. Pendekatan PBV populer di kalangan investor karena nilai buku dianggap lebih sesuai dalam menilai sebuah saham (Nugraha E. S dan Sulasmiyati S, 2017:107).

\section{METODE}

\section{Jenis Penelitian}

Jenis penelitian ini menggunakan metode asosiatif, menurut Sugiyono (2017:44) yaitu penelitian yang bertujuan untuk mengetahui pengaruh atau hubungan antara dua variabel lebih. Dalam penelitian ini pendekatan assosiatif digunakan untuk mengetahui pengaruh antara variabel, yaitu variabel Price Earning Ratio (X1) dan variabel Price Book Value (X2) terhadap variabel Keputusan Pembelian Saham (Y).

\section{Populasi}

Populasi adalah wilayah generalisasi yang terdiri atas obyek/subyek yang mempunyai kuantitas dan karakteristik tertentu yang ditetapkan oleh peneliti untuk dipelajari dan kemudian ditarik kesimpulannya (Sugiyono, 2014). Populasi dalam penelitian ini adalah seluruh perusahaan LQ 45 yang terdaftar di Bursa Efek Indonesia selama periode 2015-2019, sebanyak 45 perusahaan.

\section{Sampel}

Menurut Sugiyono (2017:149) "Sampel adalah bagian dari jumlah karakteristik yang dimiliki oleh populasi tersebut". Bila populasi besar dan peneliti tidak mungkin mempelajari yang ada pada populasi, misalnya karena keterbatasan dana, tenaga, dan waktu, maka penelitian dapat menggunakan sampel yang diambil dari populasi itu. Penelitian yang digunakan adalah purposive sampling. Menurut Sugiyono (2017:122), Purposive sampling adalah teknik penentuan sampel dengan pertimbangan tertentu. Adapun kriteria yang digunakan dalam pemilihan sampel penelitian adalah sebagai berikut:

1. Perusahaan selalu menerbitkan laporan keuangan tahunan selama periode tahun 20152019.

2. Perusahaan konsisten dalam memberikan dividen selama periode tahun 2015-2019.

3. Perusahaan tidak mengalami delisting selama periode tahun 2015-2019.

Berdasarkan kriteria tersebut maka di peroleh jumlah perusahaan yang dijadikan sampel yakni sebanyak 28 perusahaan.

\section{Operasionalisasi Variabel Penelitian}

Operasionalisasi variabel diperlukan untuk menentukan jenis dan indikator variabel-variabel yang digunakan dalam penelitian. Selain itu, proses ini juga dimaksud untuk menentukan skala pengukuran dari masing-masing variabel sehingga pengujian hipotesis dengan menggunakan alat bantu statistika dapat dilakukan secara benar.

\section{HASIL}

Untuk menentukan posisi saham terhadap harga yang terjadi di pasar (BEI) langkah yang harus dilakukan oleh para investor maupun 
calon investor adalah memperhatikan besarnya nilai hasil perhitungan rasio PER dan PBV. Dalam metode PER jika suatu saham memiliki nilai PER yang tinggi dapat diartikan sebagai saham pertumbuhan. Sebab perolehan laba tercatat membuat para investor menaruh harapan pada saham ini tetapi saham dengan PER yang tinggi sangat beresiko, sementara saham yang mempunyai nilai PER yang rendah diartikan sebagai saham bernilai (value stock) hal ini karena para investor beranggapan bahwa saham tersebut menarik untuk dibeli. Sedangkan metode PBV berpedoman pada pendapat Tandelilin dalam Nugraha (2017) "Idealnya harga pasar saham jika dibandingkan nilai buku asetnya akan mendekati 1 , sahamsaham yang mempunyai resiko harga/nilai buku yang rendah sebaiknya dibeli untuk memperoleh tingkat return yang lebih besar pada tingkat risiko tertentu.

Tabel 1. Perhitungan PER dan PBV serta posisi harga saham pada pasar modal

\begin{tabular}{|c|c|c|c|c|c|}
\hline No & Saham & PER $_{2019}$ & Posisi & $\mathrm{PBV}_{2019}$ & Posisi \\
\hline 1. & ADRO & 0,11 & Undervalued & 1,2 & Overvalued \\
\hline 2. & AKRA & 2,16 & Undervalued & 0,2 & Undervalued \\
\hline 3. & ASII & 1,05 & Undervalued & 1,5 & Overvalued \\
\hline 4. & BBCA & 9,11 & Undervalued & 1,5 & Overvalued \\
\hline 5. & $\mathrm{BBNI}$ & 0,93 & Undervalued & 1,2 & Overvalued \\
\hline 6. & BBRI & 0,36 & Undervalued & 0,6 & Undervalued \\
\hline 7. & BBTN & 10,75 & Overvalued & 0,9 & Undervalued \\
\hline 8. & BMRI & 1,27 & Undervalued & 1,7 & Overvalued \\
\hline 9. & GGRM & 1,00 & Undervalued & 2,1 & Overvalued \\
\hline 10. & HMSP & 0,32 & Undervalued & 0,1 & Undervalued \\
\hline 11. & ICBP & 2,46 & Undervalued & 5,0 & Overvalued \\
\hline 12. & INDF & 1,19 & Undervalued & 1,3 & Overvalued \\
\hline 13. & INTP & 3,69 & Undervalued & 2,9 & Overvalued \\
\hline 14. & JSMR & 1,82 & Undervalued & 1,6 & Overvalued \\
\hline 15. & KLBF & 2,98 & Undervalued & 4,5 & Overvalued \\
\hline 16. & LPPF & 0,82 & Undervalued & 6,4 & Overvalued \\
\hline 17. & $\mathrm{MNCN}$ & 0,98 & Undervalued & 1,8 & Overvalued \\
\hline 18. & PGAS & 46,24 & Overvalued & 1,6 & Overvalued \\
\hline 19. & PTBA & 0,73 & Undervalued & 0,2 & Undervalued \\
\hline 20. & PTPP & 0,86 & Undervalued & 0,1 & Undervalued \\
\hline 21. & SCMA & 1,52 & Undervalued & 0,4 & Undervalued \\
\hline 22. & SMGR & 3,08 & Undervalued & 2,2 & Overvalued \\
\hline 23. & SRIL & 0,08 & Undervalued & 0,01 & Undervalued \\
\hline 24. & TLKM & 1,43 & Undervalued & 0,2 & Undervalued \\
\hline 25. & UNTR & 7,14 & Undervalued & 1,3 & Overvalued \\
\hline 26. & UNVR & 4,40 & Undervalued & 0,6 & Undervalued \\
\hline 27. & WIKA & 0,73 & Undervalued & 0,1 & Undervalued \\
\hline 28. & WSKT & 2,05 & Undervalued & 0,1 & Undervalued \\
\hline
\end{tabular}

Sumber: data diolah 
Berdasarkan tabel di atas, dapat dijelaskan sebagai berikut:

a. Price Earning Ratio2019 (PER2019)

- Saham ADRO, AKRA, ASII, BBCA, BBNI, BBRI, BMRI, GGRM, HMSP, ICBP, INDF, INTP, JSMR, KLBF, LPPF, MNCN, PTBA, PTPP, SCMA, SMGR, SRIL, TLKM, UNTR, UNVR, WIKA, dan WSKT mempunyai nilai PER rendah. Yang artinya jika dinilai dengan metode PER berada dalam posisi Undervalued atau layak untuk dibeli oleh para investor.

- Sedangkan saham BBTN dan PGAS mempunyai nilai PER lebih tinggi. Yang artinya jika dinilai dengan metode PER berada dalam posisi Overvalued atau saham tersebut dinilai tinggi (mahal).

b. Price Book Value (PBV2019)

- Saham AKRA, BBRI, BBTN, HMSP, PTBA, PTPP, SCMA, SRIL, TLKM, UNVR, WIKA, dan WSKT mempunyai nilai PBV < dari 1 . Yang artinya jika dinilai dengan metode PBV berada dalam posisi Undervalued atau layak untuk dibeli oleh para investor.

- Sedangkan saham ADRO, ASII, BBCA, BBNI, BMRI, GGRM, ICBP, INDF, INTP, JSMR, KLBF, LPPF, MNCN, PGAS, SMGR, dan UNTR mempunyai nilai PBV > dari 1. Yang artinya jika dinilai dengan metode PBV berada dalam posisi Overvalued yang menandakan bahwa saham-saham tersebut dinilai tinggi (mahal).

\section{PEMBAHASAN}

Penelitian mengenai analisis atau penilaian harga saham sudah dilakukan oleh Afriani, E dan Asma, R (2019) yang meneliti Analisis Valuasi Harga Saham pada Perusahaan Manufaktur menggunakan Price Earning Ratio (PER), Free Cash Flow to Equity (FCFE), dan Free Cash Flow to Firm (FCFF). Hasil penelitian dengan menggunakan PER terdapat 4 perusahaan dari 12 sampel dalam kondisi overvalued yang artinya layak dijual, serta 1 perusahaan dalam kondisi fairvalued yang berarti saham sebaiknya ditahan untuk tidak dijual atau dibeli, dan 7 perusahaan dalam kondisi undervalued yang artinya saham tersebut layak untuk dibeli. Penelitian selanjutnya dilakukan oleh Nugraha, E.S dan Sulasmiyati, S (2017) yang meneliti Analisis Nilai Intrinsik Saham pada Perusahaan Sub Sektor Rokok dengan menggunakan Price Earning Ratio (PER), Price book valued (PBV), dan Price Sales Ratio (PSR). Hasil penelitian dengan menggunakan PER kondisi saham PT Gudang Garam Tbk berada pada posisi undervalued sedangkan jika berdasarkan PBV dan PSR berada pada posisi overvalued. Pada PT HM Sampoerna Tbk secara keseluruhan berada pada posisi overvalued sedangkan PT Wismilak Inti Makmur Tbk dengan menggunakan PER dan PBV nilai sahamnya overvalued, serta PSR nilai sahamnya undervalued.

Berdasarkan hasil penelitian pada perusahaan LQ 45 yang terdaftar di BEI periode 2015 - 2019 maka diperoleh nilai Price Earning Ratio (PER) dan Price book valued (PBV) serta keputusan investasi dapat dilihat di tabel 2. 
JURNAL MADANI: Ilmu Pengetahuan, Teknologi, dan Humaniora, Vol. 4, No. 2, September 2021: 126 - 132

Tabel 2. Pengambilan keputusan investasi perusahaan LQ45 dengan metode PER dan PBV

\begin{tabular}{|c|c|c|c|c|c|}
\hline No & Saham & PER & Keputusan Investasi & PBV & Keputusan Investasi \\
\hline 1. & ADRO & Undervalued & Beli Saham & Overvalued & Jual / Tahan Saham \\
\hline 2. & AKRA & Undervalued & Beli Saham & Undervalued & Beli Saham \\
\hline 3. & ASII & Undervalued & Beli Saham & Overvalued & Jual / Tahan Saham \\
\hline 4. & BBCA & Undervalued & Beli Saham & Overvalued & Jual / Tahan Saham \\
\hline 5. & $\mathrm{BBNI}$ & Undervalued & Beli Saham & Overvalued & Jual / Tahan Saham \\
\hline 6. & BBRI & Undervalued & Beli Saham & Undervalued & Beli Saham \\
\hline 7. & BBTN & Overvalued & Jual / Tahan Saham & Undervalued & Beli Saham \\
\hline 8. & BMRI & Undervalued & Beli Saham & Overvalued & Jual / Tahan Saham \\
\hline 9. & GGRM & Undervalued & Beli Saham & Overvalued & Jual / Tahan Saham \\
\hline 10. & HMSP & Undervalued & Beli Saham & Undervalued & Beli Saham \\
\hline 11. & ICBP & Undervalued & Beli Saham & Overvalued & Jual / Tahan Saham \\
\hline 12. & INDF & Undervalued & Beli Saham & Overvalued & Jual / Tahan Saham \\
\hline 13. & INTP & Undervalued & Beli Saham & Overvalued & Jual / Tahan Saham \\
\hline 14. & JSMR & Undervalued & Beli Saham & Overvalued & Jual / Tahan Saham \\
\hline 15. & KLBF & Undervalued & Beli Saham & Overvalued & Jual / Tahan Saham \\
\hline 16. & LPPF & Undervalued & Beli Saham & Overvalued & Jual / Tahan Saham \\
\hline 17. & $\mathrm{MNCN}$ & Undervalued & Beli Saham & Overvalued & Jual / Tahan Saham \\
\hline 18. & PGAS & Overvalued & Jual / Tahan Saham & Overvalued & Jual / Tahan Saham \\
\hline 19. & PTBA & Undervalued & Beli Saham & Undervalued & Beli Saham \\
\hline 20. & PTPP & Undervalued & Beli Saham & Undervalued & Beli Saham \\
\hline 21. & SCMA & Undervalued & Beli Saham & Undervalued & Beli Saham \\
\hline 22. & SMGR & Undervalued & Beli Saham & Overvalued & Jual / Tahan Saham \\
\hline 23. & SRIL & Undervalued & Beli Saham & Undervalued & Beli Saham \\
\hline 24. & TLKM & Undervalued & Beli Saham & Undervalued & Beli Saham \\
\hline 25. & UNTR & Undervalued & Beli Saham & Overvalued & Jual / Tahan Saham \\
\hline 26. & UNVR & Undervalued & Beli Saham & Undervalued & Beli Saham \\
\hline 27. & WIKA & Undervalued & Beli Saham & Undervalued & Beli Saham \\
\hline 28. & WSKT & Undervalued & Beli Saham & Undervalued & Beli Saham \\
\hline
\end{tabular}

Sumber: data diolah

\section{SIMPULAN}

Berdasarkan hasil penelitian dan pembahasan, maka kesimpulan yang diperoleh terbagi menjadi dua bagian yakni analisis saham dengan Metode Price Earning Ratio (PER) dan Metode Price Book Value (PBV). Dimana hasil perhitungan dengan menggunakan Metode Price Earning Ratio (PER) diketahui bahwa saham ADRO, AKRA, ASII, BBCA, BBNI, BBRI, BMRI, GGRM, HMSP, ICBP, INDF, INTP, JSMR, KLBF, LPPF, MNCN, PTBA, PTPP, SCMA, SMGR, SRIL, TLKM, UNTR, UNVR, WIKA, dan WSKT berada pada posisi Undervalued atau layak untuk dibeli oleh para investor. Sedangkan saham BBTN dan PGAS dimana hasil yang didapat berada pada posisi Overvalued yang menandakan bahwa sahamsaham tersebut dinilai tinggi (mahal) sehingga sebaiknya para investor menahan/menjual saham tersebut.

Lain hal dengan hasil perhitungan menggunakan Metode Price Book Value (PBV) diketahui bahwa saham AKRA, BBRI, BBTN, HMSP, PTBA, PTPP, SCMA, SRIL, TLKM, UNVR, WIKA, dan WSKT berada dalam posisi Undervalued atau layak untuk dibeli oleh para investor. Sedangkan saham ADRO, ASII, BBCA, BBNI, BMRI, GGRM, ICBP, INDF, INTP, JSMR, KLBF, LPPF, MNCN, PGAS, SMGR, 
dan UNTR berada dalam posisi Overvalued yang menandakan bahwa saham-saham tersebut dinilai tinggi (mahal) sehingga sebaiknya para investor menahan/menjual saham tersebut.

\section{PENGHARGAAN}

Pada kesempatan kali ini penulis ingin mengucapkan terimakasih kepada semua yang terlibat baik secara langsung maupun tidak langsung yang tidak bisa penulis sebutkan satu persatu. Terimakasih atas saran, masukan, dan bantuan, semoga penelitian ini bisa bermanfaat bagi semua pihak.

\section{DAFTAR PUSTAKA}

Afriani, E. dan Asma R. (2019). Analisis Valuasi Harga Saham dengan Price Earning Ratio, Free Cash Flow to Equity dan Free Cash Flow to Firm pada Perusahaan Manufaktur. Jurnal Sains Manajemen dan Kewirausahaan Vol. 3 No. 2 hal: 111-123.

Brigham, E. F. dan Joul F. H. (2010). Dasar-dasar Manajemen, Keuangan. Jakarta: Salemba Empat.

Cahyaningdyah, D. dan Ressany Y. D. (2012). Pengaruh Kebijakan Manajemen Keuangan Terhadap Nilai Perusahaan. Jurnal Dinamika Manajemen Vol. 3 No. 1 hal: 20-28.

Darmadji dan Fakhrudin. (2012). Pasar Modal di Indonesia Edisi Ketiga. Jakarta: Salemba Empat.

Darmawan A. dan Budiman R. (2018). Analisis Fundamental Harga Saham Perusahaan dengan menggunakan Metode Discounted Cash Flow dan Price Earning Ratio. Jurnal Administrasi Bisnis Vol. 63 No. 1 hal: 122-129.

Dewi, I.K. (2017). Valuasi Saham pada Perusahaan Tambang Batubara yang Terdaftar di Bursa Efek Indonesia dengan Menggunakan Metode Free Cash Flow to Equity dan Price Earning Ratio. Jurnal Eduka : Jurnal Pendidikan, Hukum, dan Bisnis Vol. 2 No. 1 hal: 76-84.

Fahmi, I. (2015). Pengantar Manajemen Keuangan Teori dan Soal. Jawab. Bandung: Alfabeta.

Kasmir. (2016). Analisis Laporan Keuangan. Jakarta: PT Raja Grafindo.

Kholis N, dkk. (2018). Faktor-Faktor yang
Mempengaruhi Nilai Perusahaan. Jurnal Analisis Bisnis Ekonomi, Vol.16 No.1 hal: 1925.

Leiwakabessy. (2018). Analisis Kinerja Keuangan Perusahaan LQ45 yang Terdaftar di Bursa Efek Indonesia. Jurnal Ekonomi Bisnis Vol 17 No 2 hal: 80-91.

Maryati, R. (2018). Faktor-faktor yang Mempengaruhi Nilai Perusahaan. IkraithHumaniora Vol.2 No.2.

Nugraha, E. S. dan Sulasmiyati, S. (2017). Analisis Nilai Intrinsik Saham dengan Relative Valuation Techniques (Studi pada Perusahaan Sub Sektor Rokok yang terdaftar di Bursa Efek Indonesia Periode 2013-2016). Jurnal Administrasi Bisnis (JAB) Vol 52 No 1 hal: 106-113.

Oktavian, R. (2019). Pengaruh Earning Per Share (EPS) dan Dividen Per Share (DPS) Terhadap Harga Saham PT. Wijaya Karya (Persero) Tbk. Jurnal Sekuritas Vol 2 No 2 hal: 156-171.

Pratama, L. A. (2019). Analisis Pembentukan Portofolio Saham Optimal Menggunakan Metode Single Index Model. Jurnal Ilmu Manajemen Vol. 16 No. 1 hal 48-60.

Ranodya B. G., dkk. (2016). Analisis Harga Wajar Saham dengan Menggunakan Metode Dividend Discount Model (DDM) dan Price Earning Ratio (PER) untuk Pengambilan Keputusan Buy, Hold, Sell (Studi Kasus Pada Saham Perusahaan yang berada pada Indeks LQ45 Periode 2014). E-Proceeding of Management Vol. 3 No. 2 hal: 1187-1196.

Rondonuwu E. F., et all. (2017). Pengaruh Current Ratio, Net Profit Margin Dan Earning Per Share Terhadap Harga Saham Di Bursa Efek Indonesia (Studi Kasus pada Sub Sektor Food and Beverages). Jurnal Riset Akuntansi Going Concern 12(2) hal: 204-212.

Sriwahyuni, E. dan Saputra R. S. (2017). Pengaruh CR, DER, ROE, TAT, dan EPS terhadap Harga Saham Industri Farmasi di BEI Tahun 20112015, Jurnal Online Insan Akuntan, Vol.2, No.1. E-ISSN: 2528-0163.

Suryanto. (2016). Valuasi Saham dengan Menggunakan Metode Price Earning Ratio (PER) pada Saham Indeks LQ45. Jurnal AdBispreneur Vol 1 No 2 hal: 137-144. 